\title{
Suplementary material: Assessment of the Greenland ice sheet - atmosphere feedbacks for the next century with a regional atmospheric model fully coupled to an ice sheet model
}

Sebastien Le clec'h et al. (2017)

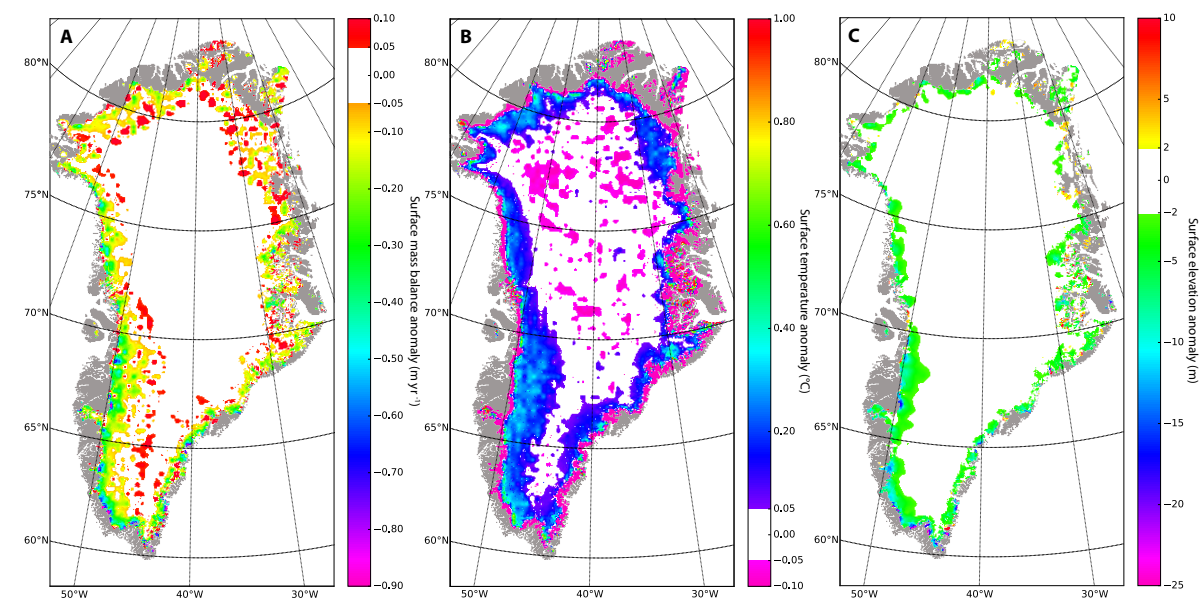

Figure S1. Mean anomalies between 2095-2100 of the 2-W experiments and the same years of the NC experiments: (a) Surface mass balance

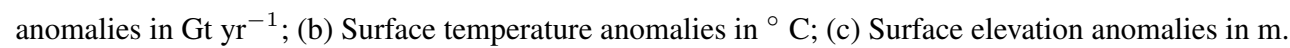



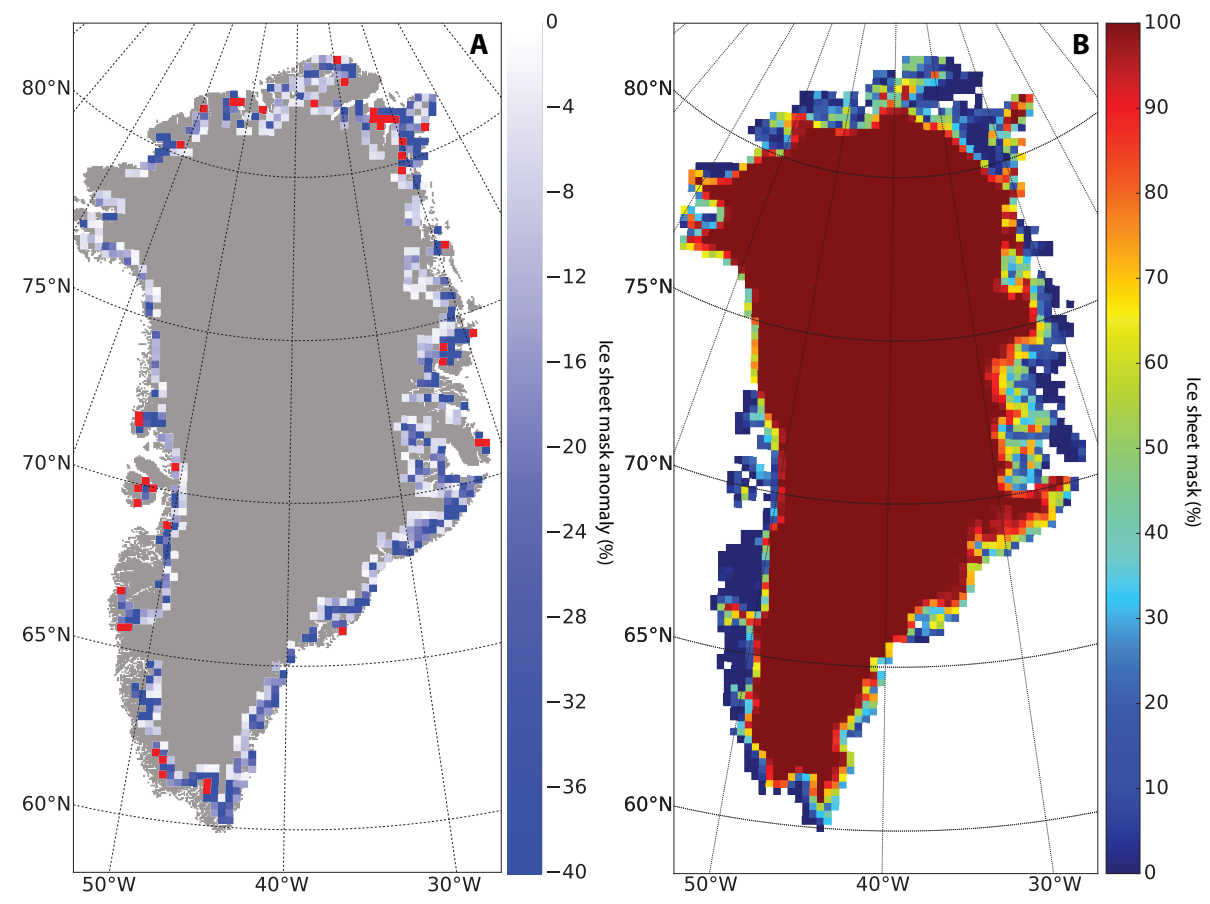

Figure S2. (a) Ice sheet mask anomalies (in \%) between the last five years (2145-2150) of the 2-W experiment and ice sheet mask of the NC experiment seen by MAR. Red colors indicate pixels loosing $100 \%$ of the ice sheet coverage. (a) Mean ice sheet mask over the last five years (2145-2150) of the $2-\mathrm{W}$ experiments. Values represent $\%$ of the grid cell covered by ice. 